\title{
gifoRSETI
}

\section{¿Arancel encubierto o barrera para-arancelaria?: Una mirada al Impuesto Selectivo al Consumo desde la perspectiva del Comercio Internacional}

\author{
Gonzalo Bernal Neumann*
}

Resumen. - En el presente artículo, el autor desarrolla el contenido del Impuesto Selectivo al Consumo y las modificaciones realizadas a su régimen en el marco del ordenamiento jurídico peruano. Posteriormente, realiza un nuevo análisis lo bajo la normativa del Comercio Internacional (reglas de la Organización Mundial de Comercio, la Comunidad Andina, los Tratados de Libre Comercio y la regulación peruana pertinente). Finalmente, concluye que el Impuesto Selectivo al Consumo sí debería seguir lo establecido por las normas del Comercio Internacional.

\begin{abstract}
The author explains the Excise Tax's implications and the adjustments made to its regimen in the Peruvian regulation. Then he analyses the previous aspects according to the International Commerce's legislation (rules from the World Trade Organization, the Andean Community, Free Trade Agreements signed by Peru and the associated Peruvian law). Finally, the author establishes that the Excise Tax should obey the International Commerce's precepts.
\end{abstract}

* Asociado principal del área de comercio exterior y derecho aduanero del Estudio Echecopar - Baker \& Mckenzie International. Abogado por la Pontificia Universidad Católica del Perú - PUCP (2005) y Máster en Derecho Internacional y Economía por el World Trade Institute, Universidad de Berna, Suiza (2011). 


\section{Introducción}

A partir de las recientes modificaciones en mayo del 2018 al Decreto Supremo ${ }^{\circ}$ 055-99-EF, el cual aprobó el Texto Único Ordenado de la Ley del Impuesto General a las Ventas e Impuesto Selectivo al Consumo ("TUO"), enfocadas a actualizar las tasas y bienes gravados con el Impuesto Selectivo al Consumo ("ISC") en el Perú, se generó un debate en torno a si el ISC, como impuesto interno indirecto, se encuentra bajo el alcance de los principios y obligaciones generales suscritos por nuestro país en materia de comercio internacional.

La discusión se centraba básicamente en que las materias tributarias, intrínsecas a la soberanía del Estado, no están ni deberían estar bajo los alcances de los principios de comercio internacional, salvo los principios de no discriminación ${ }^{1}$.

El presente artículo desarrolla de manera sucinta que la aplicación de los Estados a gravar ciertas actividades y bienes con el ISC está regulada no solo por los principios tributarios y administrativos de los países sino por los términos y condiciones establecidos en los Acuerdos Multilaterales (Organización Mundial de Comercio-OMC), los Tratados Regionales (ej. Comunidad Andina) y Acuerdos Comerciales Bilaterales (ej. TLC Perú-EE.UU.; TLC Perú-Unión Europea) si tienen un impacto e influencia en el comercio de bienes, transporte o servicios.

Asimismo, los impuestos indirectos como el ISC no solo deben de juris o de facto generar un trato igualitario entre producción local y extranjera (Principio de Trato Nacional) o no establecer un trato desigual entre países (Principio de Nación Más Favorecida) sino además deben ser previsibles, transparentes y no deben determinarse como obstáculos o barreras innecesarias al movimiento transfronterizo ni interferir, e impedir el acceso o permanencia de un nuevo inversionista en los mercados.

No solo la normativa de comercio es clara al respecto sino la jurisprudencia internacional es vasta en ratificar lo antes señalado. Sin embargo, lo que se ve en la práctica es que cada vez más Estados utilizan la imposición del ISC como mecanismo de protección a sus industrias o con fines recaudatorios, no implementando procedimientos de calidad regulatoria para su determinación.

Dentro de nuestro análisis, la imposición del ISC permite ciertas "flexibilidades" que ningún otro tributo goza, teniendo en consideración que su naturaleza es gravar bienes suntuosos o que generan externalidades que afectan a la economía del mercado regulado. No obstante, dichas flexibilidades si no tienen ciertos límites o condiciones, como son las que incorpora el marco normativo de comercio internacional, puede conllevar a un "arancel encubierto", es decir, un impuesto que en frontera obstruye y dinamita el libre comercio o, por otro lado, puede ser

1 VAN DEN BOSSCHE, Peter y ZDOUC, Werner. The Law and Policy of the World Trade Organization. 3era Edición. Cambridge, Cambridge University Press, 2012. 
considerado una barrera para-arancelaria.

Por ello, es relevante analizar el ISC como medida a la luz de la normativa de comercio, lo cual trataremos de revisar brevemente en las siguientes líneas.

\section{Naturaleza y elementos del ISC en el marco normativo general peruano}

\section{i. Antecedentes del régimen del ISC en el Perú}

El Decreto Supremo No 055-99-EF, aprobó el TUO en cumplimiento de lo dispuesto por la Cuarta Disposición Final de la Ley No 27039 (Ley que modifica el Decreto Legislativo $N^{o}$ 821, Ley del Impuesto General a las Ventas e Impuesto Selectivo al Consumo). De igual manera, su reglamento fue aprobado mediante el Decreto Supremo No 29-94-EF (en adelante, el "Reglamento").

El artículo 50 del TUO señala que constituyen operaciones gravadas con el ISC: (a) La venta en el país a nivel de productor y la importación de los bienes especificados en los Apéndices III y IV; (b) La venta en el país por el importador de los bienes especificados en el literal A del Apéndice IV; y (c) Los juegos de azar y apuestas, como por ejemplo, loterías, bingos, rifas, sorteos y eventos hípicos. Asimismo, el artículo 52 regula el nacimiento de la obligación tributaria y el artículo 53 enumera a los sujetos obligados al pago del impuesto. $\mathrm{Al}$ respecto, se afirma que, si bien el responsable del pago del impuesto será el fabricante o el importador de los bienes, "la carga económica del mismo la soporta el consumidor final"2.

Por su parte, los artículos 55 y siguientes regulan la base imponible precisando que el ISC se aplicará bajo tres sistemas distintos en función de los bienes de que se trate y que se detallan en los respectivos Apéndices contenidos en el TUO. Se trata de los sistemas: (a) Al Valor, que se determina aplicando sobre la base imponible la tasa fijada en el literal A del Apéndice IV; (b) Específico, que se determina aplicando un monto fijo por volumen vendido o importado, conforme al valor establecido en el Apéndice III y el literal B del Apéndice IV; y (c) Al Valor según Precio de Venta al Público, que se determina aplicando la tasa fijada en el literal C del Apéndice IV sobre el precio de venta al público sugerido por el productor o el importador, multiplicado por un factor determinado.

Además, el artículo 61 del TUO permite que, a través de un Decreto Supremo refrendado por el Ministro de Economía y Finanzas, se modifiquen las tasas y/o montos fijos, así como los bienes contenidos en los respectivos Apéndices.

El artículo 61, párrafo final, del TUO señala que tratándose de los bienes mencionados en el Apéndice IV las tasas deben "encontrarse dentro de los rangos mínimos y máximos que se indican". Dichos rangos fluctúan, por ejemplo, en el caso de cigarrillos entre $20 \%$ y $300 \%$. Mientras que en el caso de las gaseosas, oscila entre el 1\% y 150\%. En contraste, en el caso del Pisco, las modificaciones de sus

2 ZOLEZZI MOLLER, Armando. El Impuesto a las Ventas - Su evolución en el Perú. Lima, en Revista del Instituto Peruano de Derecho Tributario, núm. 05, 1983, p.23. 
gravámenes fijos deberán fluctuar entre 1.50 y 2.50 soles. [...]

Sobre este último punto, es necesario recordar que el Tribunal Constitucional en el caso $\mathrm{N}^{\circ}$ 02724-2007-AA, declaró que originalmente el artículo 61 del TUO vulneraba el principio de legalidad. No obstante, deslindó la posibilidad que, de manera excepcional, el Poder Ejecutivo regule ciertos aspectos del tributo, en tanto esta no sea una remisión "en blanco", sino que la ley deberá establecer los parámetros aplicables al tributo a fin de evitar la desnaturalización de la naturaleza del mismo. En esa línea, se modificó el artículo 61 del TUO considerando los parámetros indicados, subsanando, de esa manera, lo resuelto por el Tribunal Constitucional.

A pesar de dicha inclusión en el citado artículo, es de nuestra opinión que los parámetros propuestos permiten cierta discrecionalidad, manteniendo vicios en su diseño y estructura, como por ejemplo el extenso rango de las tasas o la generalidad en la descripción de la lista de bienes afecta al ISC. La sola remisión al artículo 61 del TUO no debería validar una modificación, creyendo que es necesario sustentar el por qué se está gravado con la tasa identificada o por qué el bien debe encontrarse afecto al impuesto. Dicha discrecionalidad puede seguir erosionando principios básicos, como el principio de reserva de ley en materia tributaria.

\section{ii. Análisis de las modificaciones realizadas al régimen del ISC}

El 09 de mayo de 2018 en Edición Extraordinaria del diario oficial El Peruano, pero divulgada el 10 de mayo, se publicaron cinco Decretos Supremos que introdujeron modificaciones al Apéndice IV del TUO:

- $\quad$ Decreto Supremo Nº91-2018-EF, que modifica los bienes y las tasas referidas a bebidas azucaradas.

- Decreto Supremo $N^{\circ}$ 092-2018-EF, que modifica los las tasas referidas a cigarrillos.

- $\quad$ Decreto Supremo No 093-2018-EF, que modifica los bienes y las tasas referidas a bebidas alcohólicas.

- $\quad$ Decreto Supremo Nº94-2018-EF, que modifica los bienes y las tasas referidas a combustibles.

- $\quad$ Decreto Supremo No 095-2018-EF, que modifica los bienes y las tasas referidas a vehículos nuevos y/o usados.

Las modificaciones al referido apéndice introducen nuevos bienes afectos al Impuesto Selectivo al Consumo, estableciendo nuevos criterios de afectación y modificando las tasas aplicables, de conformidad con los parámetros mínimos y máximos establecidos en el TUO.

$\mathrm{Al}$ respecto, podemos apreciar que a pesar de que los bienes y tasas modificadas gravados con el ISC estaban incluidos en la relación de productos y parámetros establecidos en el artículo 61 del TUO, existen ciertos vicios desde la perspectiva 
de comercio exterior que no fueron revisados en su oportunidad. El objeto de cuestionamiento de las modificaciones bajo análisis, desde la perspectiva de la normativa comercial, no radica en el incremento ni en la exigencia del ISC per se, sino que radica en ciertos elementos contenidos en los Decretos Supremos, en específico, al diseño y la estructura de la aplicación del ISC a los bienes para la determinación de las tasas imponibles correspondientes.

Cabe resaltar que los vicios que conciernen la aprobación de estos instrumentos normativos se originan desde su publicación extraordinaria, donde inclusive fue omitida la exposición de motivos. Determinándose así, modificaciones a las tasas y bienes del ISC carentes de sustento técnico. De tal manera que, en la práctica su aplicación podría conllevar a los sujetos gravados a sufrir un grave perjuicio irrazonable e injustificado.

A la luz de lo expuesto, a continuación, procederemos a analizar el diseño y estructura de las modificaciones al ISC a la luz del normativo de comercio internacional a fin de identificar la existencia de potenciales vulneraciones al marco jurídico internacional aplicable al presente caso.

\section{Los impuestos indirectos y la normativa de Comercio Internacional}

\section{i. Regulación multilateral - Las normas de la Organización Mundial de Comercio (OMC)}

\section{a. Los impuestos indirectos como barreras para-arancelarias en GATT 94}

El ISC, como impuesto indirecto, puede ser considerado una medida o restricción para-arancelaria. A la luz de los Acuerdos de la Organización Mundial de Comercio (en adelante, "OMC"), vigentes y aplicables al Perú, y el Centro de Comercio Internacional, señalan que dentro de la clasificación de medidas comerciales para-arancelarias o no arancelarias se encuentran disposiciones distintas de las arancelarias que aumentan el costo de las importaciones de manera similar, es decir, en un porcentaje fijo o en una cantidad fija, abarcando impuestos internos y cargas adicionales ${ }^{3}$.

Estas medidas pueden perseguir diversos fines, entre los cuales se busca " $e l$ aumento o manutención de los ingresos fiscales". Entre ellas están los impuestos especiales, específicos o impuestos y gravámenes para categorías de productos sensibles, es decir el ISC ${ }^{4}$.

3 Organización Mundial de Comercio (2012) Identificando las medidas no arancelarias. Centro de Comercio Internacional Sitio web: http://www.intracen.org/itc/analisis-mercados/medidasno-arancelarias/identificando-las-medidas-no-arancelarias/

Consulta realizada el día 11 de diciembre de 2018.

4 Conferencia de las Naciones Unidas sobre el Comercio y el Desarrollo. (2012). Clasificación Internacional De Medidas No Arancelarias. Naciones Unidas Sitio web: http://unctad.org/es/PublicationsLibrary/ditctab20122_es.pdf. Consulta realizada el 11 de diciembre de 2018 


\section{b. Los impuestos indirectos bajo el Principio de No Discriminación en el GATT 94}

El Perú, mediante Resolución Legislativa No 26407, vigente desde el 1 de enero de 1995, aprobó e incorporó a la legislación nacional el "Acuerdo por el que se establece la Organización Mundial del Comercio y los Acuerdos Comerciales contenidos en el Acta Final de la Ronda de Uruguay" suscritos el 15 de abril de 1994 en Marrakech, Marruecos. Dichos Acuerdos incluyen, entre otros, el Acuerdo General sobre Aranceles Aduaneros y Comercio - GATT 94.

En virtud de ello, el Perú es considerado País Miembro de la OMC y se encuentra obligado a cumplir con las normas recogidas en los Acuerdos $\mathrm{OMC}$, en este caso, el GATT 94, las cuales se encuentran relacionadas al establecimiento de reglas para el comercio de mercancías.

El GATT 94 tiene por objetivo establecer reglas que prohíben la implementación y regulación de medidas tanto arancelarias como para-arancelarias que restrinjan el comercio de bienes entre los Países Miembros de la OMC.

Las principales disposiciones están enfocadas a la no discriminación en el comercio. Entre dichas disposiciones, el artículo I del GATT 94, regula el principio de Nación Más favorecida ("igual trato para todos los demás"), el cual señala lo siguiente en su primer párrafo:

"1. Con respecto a los derechos de aduana y cargas de cualquier clase impuestos a las importaciones o a las exportaciones, o en relación con ellas, (...), cualquier ventaja, favor, privilegio o inmunidad concedido por una parte contratante a un producto originario de otro país o destinado a él, será concedido inmediata e incondicionalmente a todo producto similar originario de los territorios de todas las demás partes contratantes o a ellos destinado." (Énfasis agregado).

A la luz de la norma mencionada previamente, podemos apreciar que el artículo I del GATT 94 prescribe que los miembros de la OMC deben conceder de manera inmediata e incondicional a todo producto similar originario de los territorios de todos los demás miembros de la OMC o a ellos destinado cualquier ventaja, favor, privilegio o inmunidad concedidos a un producto originario de otro país o a él destinado. Asimismo, este principio implica que cada vez que un país reduce un obstáculo al comercio o abre un mercado, tiene que aplicarlo análogamente para los mismos productos de todos los demás países miembros de la OMC.

Adicionalmente, el artículo III del GATT 94 establece el principio de Trato Nacional ("igual trato para nacionales y extranjeros") el cual señala lo siguiente:

"1. Las partes contratantes reconocen que los impuestos y otras cargas interiores, así como las leyes, reglamentos, (...) no deberían aplicarse a los productos importados o nacionales de manera que se proteja la producción nacional. 
2. Los productos del territorio de toda parte contratante importados en el de cualquier otra parte contratante no estarán sujetos, directa ni indirectamente, a impuestos interiores $u$ otras cargas interiores, de cualquier clase que sean, superiores a los aplicados, directa o indirectamente, a los productos nacionales similares. (...)" (Énfasis agregado).

El referido artículo, define como principio la no discriminación entre bienes importados y los bienes nacionales. En este sentido, los países miembros de la OMC (entre ellos el Perú) reconocen que las mercancías importadas y las producidas en el país deben recibir el mismo trato, de manera que no se busque proteger la producción nacional. En ese sentido, los productos del territorio de toda Parte contratante importados en el de cualquier otra parte contratante no estarán sujetos a impuestos interiores $\mathrm{u}$ otras cargas interiores superiores a los aplicados a los productos nacionales similares.

De acuerdo a lo anterior, es claro señalar que si la aplicación del ISC genera una distinción ilegítima (de jure o de facto) entre bienes importados y nacionales ${ }^{5}$ o entre bienes importados originarios de distintos países ${ }^{6}, \mathrm{y}$ dicha distinción puede evidenciarse, podríamos estar ante un caso de vulneración del principio de no discriminación.

\section{c. Los impuestos indirectos bajo el Principio de Publicidad y Transparencia en el GATT 94}

El artículo X del GATT 94 contempla disposiciones básicas sobre el principio de transparencia, el cual obliga a los países miembros de la OMC a cumplir con la debida publicación de derechos u otras medidas gubernamentales (ej. impuestos internos) que puedan influir en sus importaciones o exportaciones.

$\mathrm{Al}$ respecto, el referido artículo señala lo siguiente:

“Artículo X del GATT 94: Publicación y aplicación de los reglamentos comerciales

1. Las leyes, reglamentos, decisiones judiciales y disposiciones administrativas de aplicación general que cualquier parte contratante haya puesto en vigor y que se refieran a la clasificación o a la valoración

5 En el caso de "CE - Amianto", el Órgano de Apelación OMC señaló que la aplicación de impuestos y/o reglamentos interiores de una manera que afecte a la relación de competencia, en el mercado, entre los productos de origen nacional y los productos importados de que se trata, de manera que se proteja la producción nacional, puede ser considerado una vulneración al principio de trato nacional. (Informe del Órgano de Apelación, Comunidades Europeas Medidas que afectan al amianto y a los productos que contienen amianto, párrafo. 98)

6 El Grupo Especial OMC en "Canadá - Automóviles" ha indicado que puede existir discriminación de facto cuando existe un trato menos favorable a los productos similares de determinados Miembros de la OMC. El Grupo Especial ha tenido en cuenta la posibilidad de que la limitación a determinados importadores de la exención de derechos de importación al amparo de la medida tenga como resultado una discriminación de facto. (Informe del Grupo Especial, Canadá Determinadas medidas que afectan a la industria del automóvil, párrafo. 31) 
en aduana de productos, a los tipos de los derechos de aduana, impuestos u otras cargas, o a las prescripciones, restricciones o prohibiciones de importación o exportación, o a la transferencia de pagos relativa a ellas, o a la venta, la distribución, el transporte, el seguro, el almacenamiento, la inspección, la exposición, la transformación, la mezcla o cualquier otra utilización de dichos productos, serán publicados rápidamente a fin de que los gobiernos y los comerciantes tengan conocimiento de ellos. (...) Las disposiciones de este párrafo no obligarán a ninguna parte contratante a revelar informaciones de carácter confidencial cuya divulgación pueda constituir un obstáculo para el cumplimiento de las leyes o ser de otra manera contraria al interés público o pueda lesionar los intereses comerciales legítimos de empresas públicas o privadas.

2. No podrá ser aplicada antes de su publicación oficial ninguna medida de carácter general adoptada por una parte contratante que tenga por efecto aumentar el tipo de un derecho de aduana u otra carga sobre la importación en virtud del uso establecido y uniforme, o que imponga una nueva o más gravosa prescripción, restricción o prohibición para las importaciones o para las transferencias de fondos relativas a ellas. (...)." (Énfasis agregado).

Sobre el particular, el párrafo 1 del artículo X del GATT 94 establece la obligación que todos los países miembros de la OMC publiquen las medidas de carácter general que afectan directamente el comercio (ej. impuestos especiales), de tal manera que: (i) la información sea proporcionada de manera no discriminatoria; (ii) que sea de fácil acceso para garantizar que los interesados, entre ellos el sector privado, se familiaricen con sus alcances y disposiciones 7 y (iii) que se publique de manera eficaz y oportuna.

El objetivo es que otros países miembros de la OMC y la industria, las cuales pueden verse afectadas por las medidas gubernamentales que imponen restricciones, procedimientos, requisitos y otras cargas en operaciones de comercio exterior, deben tener una oportunidad razonable para adquirir información confiable sobre tales medidas y en consecuencia, proteger y ajustar sus actividades $^{8}$. Finalmente, cabe señalar que para cumplir a cabalidad con las obligaciones del artículo X GATT 94, resulta necesaria la publicación de todos los elementos esenciales ${ }^{9}$ que la justifiquen.

7 Informe Grupo Especial de la OMC en el caso CE - Productos de tecnología de la información.

8 Informe del Órgano de Apelación OMC en "Estados Unidos - Restricciones aplicadas a las importaciones de ropa interior de algodón y fibras sintéticas o artificiales".

9 El Grupo Especial en el caso "República Dominicana - Importación y venta de cigarrillos", se discutió si unas encuestas aplicadas por el Banco Central de República Dominicana, que servían de base para calcular el impuesto aplicable a los cigarrillos, eran una medida cubierta por el artículo X:1 del GATT de 1994. En su análisis, el Grupo Especial constató que, aunque las encuestas en sí mismas no eran disposiciones administrativas de aplicación general, éstas constituían "un elemento esencial de una disposición administrativa: la determinación de la base imponible de los cigarrillos." (Informe del grupo especial, República Dominicana - Importación y venta de cigarrillos, párr. 7.405.) En virtud de ese carácter de elemento esencial, el grupo especial concluyó que "[a] fin de conocer el proceso de establecimiento de la base imponible para la aplicación del 
A la luz de lo anterior, analizando si el ISC como medida puede calzar dentro de las obligaciones del artículo X.1 del GATT 94, podemos apreciar que este generalmente es una medida de alcance general (gravamen aplicable no solo a un sector en particular), por lo tanto, debió cumplir con los lineamientos mandatorios establecidos por el párrafo 1 del artículo X GATT 94.

Otro elemento de análisis es cuál es el sujeto pasivo, la hipótesis de incidencia y el hecho imponible del ISC, ya que, a nuestro entender, si en la práctica afecta únicamente a importadores, o a productos que no se producen localmente, podríamos estar hablando de un arancel encubierto como señaláramos previamente. En ese caso, al tener un carácter intrínsecamente vinculado a las operaciones de comercio exterior, el principio de publicación es mucho más relevante, siendo esencial para los sujetos afectados sobre la predictibilidad y certeza de los efectos de la imposición del impuesto en cuestión.

En esa línea, creemos que la imposición del ISC podría vulnerar el artículo X.1 GATT 94, si no se publica de manera eficaz y oponible. Es decir, si la publicación del impuesto no sigue las formalidades planteadas para su oponibilidad. Así mismo, se vulneraría dicho artículo si el ISC no tiene una exposición de motivos publicada (sustento científico, técnico y económico) que acredite los elementos por los cuales realiza el incremento, reducción y exoneración de las tasas imponibles del ISC sobre los bienes afectados, y la metodología utilizada para ello.

Finalmente, podemos observar que el artículo X.2 del GATT 94 (principio de transparencia y oportunidad de consultas previas), señala que las autoridades competentes deben pre-publicar medidas de carácter general ${ }^{10}$ que tienen como efecto el aumento de cargas sobre la importación. De la norma citada se desprende que si las autoridades competentes, al modificar e incrementar la tasa del ISC, y esta afecta de manera exclusiva, directa y material a las importaciones, debieron ser pre-publicadas como etapa previa a su entrada en vigencia, teniendo en cuenta las implicancias que tendría como carga en las operaciones de comercio exterior.

\section{d. Otros acuerdos comerciales}

Sin perjuicio del análisis anterior, los impuestos indirectos tales como el ISC también pueden ser objeto de cuestionamiento bajo otros acuerdos comprendidos en el marco normativo de la OMC, como es el caso del Acuerdo sobre Subvenciones y Medidas Compensatorias ("ASMC"). En ese sentido, resulta

Impuesto Selectivo al Consumo a los cigarrillos, los gobiernos y los comerciantes tendrían derecho a obtener información sobre los resultados de la encuesta, así como sobre la metodología utilizada para realizarla". (Informe del grupo especial, República Dominicana - Importación y venta de cigarrillos, párrafo. 7.407.)

10 El párrafo 2 del Artículo X del GATT 94 se refiere simplemente a una "medida" y por tanto abarca una categoría aún más amplia, a saber, cualquier acto u omisión de un Miembro de la OMC. De ello se deduce por tanto que los redactores pretendían incluir una gama amplia de medidas que pueden afectar al comercio y a los comerciantes." (Informe del Grupo Especial en CE Productos de tecnología de la información. párrafo 7.1097) 
necesario destacar el criterio empleado en el caso Indonesia - Automóviles'11, en el cual el Grupo Especial constató que las exenciones del derecho y del impuesto sobre las ventas con arreglo al Programa Nacional de Automóviles de 1996 eran subvenciones específicas que habían causado "un grave perjuicio a las importaciones de las Comunidades Europeas a la luz del inciso c) del artículo 5 del ASMC."

\section{ii. Regulación regional - Las reglas de la Comunidad Andina \\ a. Los impuestos indirectos a la luz de las normas contenidas en la Comunidad Andina}

En la Comunidad Andina (CAN) existe una serie de disposiciones legales de carácter supranacional que proscriben la aplicación de gravámenes y/o restricciones injustificadas al comercio. La pregunta es si un impuesto indirecto, como lo es el ISC, puede ser considerado un gravamen o restricción injustificada al comercio, y por tanto, podría ser denunciado ante las autoridades competentes CAN.

Las normas de la Comunidad Andina establecen una obligación para los Países Miembros de consolidar un Programa de Liberación a través de la eliminación de todo tipo de gravámenes y restricciones ${ }^{12}$; dicha obligación viene aparejada con la prohibición que tienen dichos Países Miembros de aplicar o establecer ese tipo de medidas comerciales ${ }^{13}$.

Al respecto, el Acuerdo de Cartagena define "gravámenes y restricciones" de la siguiente manera:

"Artículo 73.- Se entenderá por 'gravámenes' los derechos aduaneros y cualesquier otros recargos de efectos equivalentes, sean de carácter fiscal, monetario o cambiario, que incidan sobre las importaciones. No quedarán comprendidos en este concepto las tasas y recargos análogos cuando correspondan al costo aproximado de los servicios prestados.

Se entenderá por 'restricciones de todo orden' cualquier medida de carácter administrativo, financiero o cambiario, mediante la cual un País Miembro impida o dificulte las importaciones, por decisión unilateral. No quedarán comprendidas en este concepto la adopción y el cumplimiento de medidas destinadas a la:

11 En este caso, se discutieron dos Programas correspondientes a los años 1993 y 1996 emitidos por el Gobierno Indonesio que proporcionaban ventajas en materia tributaria, tales como la exención del impuesto sobre el lujo o sobre los derechos de importación para los automóviles que reúnan las condiciones (de contenido local, etc.), o Compañías de automóviles indonesias. (Indonesia Determinadas medidas que afectan la industria del automóvil (DS54), Informe del Grupo Especial.

12 El Artículo 71 del Acuerdo de Cartagena dispone lo siguiente: "El Programa de Liberación de bienes tiene por objeto eliminar los gravámenes y las restricciones de todo orden que incidan sobre la importación de productos originarios del territorio de cualquier País Miembro".

13 El Artículo 77 del Acuerdo de Cartagena dispone lo siguiente: "Los Países Miembros se abstendrán de aplicar gravámenes y de introducir restricciones de todo orden a las importaciones de bienes originarios de la Subregión". 
a) Protección de la moralidad pública;

b) Aplicación de leyes y reglamentos de seguridad;

c) Regulación de las importaciones o exportaciones de armas, municiones y otros materiales de guerra y, en circunstancias excepcionales, de todos los demás artículos militares, siempre que no interfieran con lo dispuesto en tratados sobre libre tránsito irrestricto vigentes entre los Países Miembros;

d) Protección de la vida y salud de las personas, los animales y los vegetales;

e) Importación y exportación de oro y plata metálicos;

f) Protección del patrimonio nacional de valor artístico, histórico o arqueológico; $y$

g) Exportación, utilización y consumo de materiales nucleares, productos radiactivos o cualquier otro material utilizable en el desarrollo o aprovechamiento de la energía nuclear" (Énfasis agregado).

Como puede apreciarse, el concepto de "gravamen" implica la aplicación, por parte de un País Miembro, de cualquier recargo (monetario, fiscal o de cualquier otra índole) con efectos equivalentes a los derechos aduaneros, y que este recargo tenga incidencia en las importaciones de productos originarios de los demás Países Miembros. La excepción a esto es el pago de tasas por servicios prestados al momento de la importación de los productos.

Sobre la definición de "gravamen", la Secretaría General de la Comunidad Andina ha señalado lo siguiente:

"(..) al comprenderse en el concepto de gravamen "cualesquier otros recargos de efectos equivalentes" a los derechos aduaneros o arancel, se está sancionando todo tipo de cargo al comercio intrasubregional, sin excepciones, salvo las expresamente previstas en el Acuerdo de Cartagena. En este sentido, la teoría económica entiende que los efectos de un arancel pueden ser de diversa índole, de los cuales es el principal el hecho que "un arancel incrementa el precio de un bien en el país importador" y así "aumenta el precio recibido por los productores nacionales de dicho bien" (KRUGMAN, Paul y OBSTFELD, Maurice. Economía Internacional. Teoría y Política. Madrid: Mc Graw Hill, 1994, p. 208 y ss.). Por tanto serían comprensibles en los alcances del Artículo 72 primer párrafo, todos aquellos recargos que eleven el precio de las importaciones a la Subregión sin que importe necesariamente su calificativo como recargos tributarios, cambiarios o monetarios ${ }^{14 "}$ (Énfasis agregado).

Por su parte, la jurisprudencia del Tribunal de Justicia de la Comunidad Andina (en adelante, el Tribunal) ha desarrollado el concepto de gravamen de la siguiente manera:

14 Resolución 179 de la Secretaría General (Por la cual se resuelve el recurso de reconsideración presentado por el Gobierno del Ecuador contra la Resolución 139 de la Secretaría General de la Comunidad Andina que calificó como gravamen a la importación a la cuota redimible para la provisión de recursos destinados a la Corporación de Promoción de Exportaciones e Inversiones, CORPEI, del Ecuador). Publicada en la Gaceta Oficial del Acuerdo de Cartagena N 401, del 19 de enero de 1999. 
"Lo primero que debe destacar El Tribunal, en cuanto a la definición del concepto de gravamen que hace la norma comunitaria, es que ella no corresponde al criterio técnico tributario que lo restringe al campo de los impuestos, sino que cubre una generalidad de situaciones y dominios que trascienden el ámbito de la tributación, para cobijar bajo su manto todas aquellas situaciones con las cuales se pretenda recargar el valor de las importaciones que, por estar realizándose dentro de una zona de libre comercio, no deben gravarse con suma alguna derivada del hecho mismo de la importación, a no ser que se trate del cobro de los servicios que, directamente relacionados con tal hecho, deba sufragar el importador como contraprestación por tales servicios, generalmente constituidos por operaciones de descargue, estiba y desestiba, utilización de puertos y hangares, bodegajes, trámites concernientes al levante de las mercancías y demás usuales dentro del comercio internacional de bienes.

Nótese cómo la definición legal no restringe el concepto de gravámenes a los derechos aduaneros sino que lo amplía, de una manera bien generosa, a "cualesquier otros recargos de efectos equivalentes", sin importar que tales recargos tengan tal o cual denominación, ni tampoco su naturaleza, que bien puede ser de carácter fiscal, de carácter monetario o de carácter cambiario y cuyo único condicionante es que incidan sobre las importaciones, encareciéndolas o dificultándolas.

(...)

Es perfectamente entendible para El Tribunal el empeño del legislador andino en prevenir cualquier intento de desviación, que utilizando la vía de los recargos monetarios, cualquiera fuere su naturaleza, su propósito y su destinación, pudieran realizar los Países Miembros, desnaturalizando con ello el programa de liberación que es, por cierto, la esencia del mercado común y uno de los fines propios del Acuerdo de Integración Subregional15" (Énfasis agregado).

Queda claro entonces que el concepto de "gravamen" en el marco de la Comunidad Andina no se limita a temas arancelarios sino que puede incluir asuntos de carácter tributario tal como la imposición de un impuesto como el ISC. Si bien no existe un antecedente jurisprudencial específico relativo a la calificación de un tributo interno (igual o similar al ISC) como gravamen, en la medida que se demuestre que el incremento, reducción o exoneración del ISC incide sobre las importaciones procedentes de otros Países Miembros de la Comunidad Andina, podría tenerse un resultado favorable ante la Secretaría General de la Comunidad Andina. Así lo ha reconocido además el Tribunal en la siguiente sentencia:

"En aplicación del principio general de la libre circulación de mercancías en el comercio subregional, que consagra el Acuerdo de Cartagena, no es acertado sostener, como lo ha hecho la parte demandada, que el concepto de 'gravamen' debe ser interpretado restrictivamente, cuando la norma comunitaria tiene por objeto consolidar el compromiso de los Países

15 Sentencia del Proceso 12-AN-99. Acción de Nulidad interpuesta por la Corporación de Promoción de Exportaciones e Inversiones (CORPEI) de Ecuador contra las Resoluciones $N^{\circ} 139$ del 14 de octubre de 1998 y N 179 del 14 de enero de 1999, expedidas por la Secretaría General de la Comunidad Andina. Publicada en la Gaceta Oficial del Acuerdo de Cartagena $N^{\circ} 520$, del 20 de diciembre de 1999. 
Miembros de eliminar los gravámenes y restricciones de todo orden e imponer una libertad de intercambio comercial. Son, por el contrario, las excepciones o limitaciones a la libertad de circulación de bienes y servicios, las que deben ser interpretadas en forma estricta.

Podría decirse que el concepto de gravamen es de carácter residual, en el sentido de que todos los recargos que encarezcan las importaciones y no configurables dentro del concepto de 'tasas', han de ser consideradas como 'gravámenes'16"' (Énfasis agregado).

Cabe resaltar que el precitado artículo 73 del Acuerdo de Cartagena dispone que la excepción a la aplicación de un gravamen es el pago de tasas por servicios prestados al momento de la importación de los productos; sin embargo, las excepciones a la aplicación de "restricciones 17" comerciales incluyen -entre otras-, la "protección de la vida y salud de las personas".

En consecuencia, cualquier recargo fiscal que incida en las importaciones que se realicen de productos originarios de Bolivia, Colombia y Ecuador hacia el Perú, a los cuales se les aplique dicho incremento y las encarezca, no podrá ampararse en razones de medio ambiente o salud pública para no ser considerado un gravamen. Conforme a lo dispuesto por el Acuerdo de Cartagena, solo las medidas administrativas o cambiarias que impidan o dificulten las importaciones, se considerarán restricciones justificadas en caso se sustenten en razones de salud pública.

Adicionalmente, es importante resaltar que el marco normativo andino tiene decisiones relacionadas en materia de tributación: la Decisión 59918 Armonización de Aspectos Sustanciales y Procedimentales de los Impuestos Tipo Valor Agregado y la Decisión 600 - Armonización de los Impuestos Tipo Selectivo al Consumo. Ambas Decisiones determinan ciertas reglas y condiciones a considerar por los Países Miembros al momento de determinar el ISC, teniendo como objetivo una armonización a través de los mismos lineamientos básicos y, en lo posible, no registrar diferencias estructurales en las normativas de los Países Miembros para que los agentes económicos puedan tener un ámbito de claridad y concurrencia libre y comparable.

Cabe resaltar, por ejemplo, en la Decisión 599, las reglas sobre modificaciones en el ISC en las legislaciones internas:

\section{"Artículo 3.- Régimen de armonización andino sobre imposición indirecta al consumo.}

El régimen de armonización de la imposición indirecta al consumo para los Países Miembros estará comprendido por los siguientes tributos:

16 Sentencia del Proceso 19-AI-99. Acción de Incumplimiento interpuesta por la Secretaría General de la Comunidad Andina contra la República de Ecuador, por aplicar una medida calificada como "gravamen" a las importaciones de la Subregión. Publicada en la Gaceta Oficial del Acuerdo de Cartagena $\mathrm{N}^{\circ} 588$ del 02 de agosto de 2000.

17 A diferencia del gravamen, una restricción al comercio -en los términos del Acuerdo de Cartagena- es cualquier medida de carácter administrativo, financiero o cambiario mediante la cual un País Miembro, de manera unilateral, impida o dificulte las importaciones.

18 La Decisión 599 está vigente desde el 01 de enero de 2008. 
1. La imposición tipo valor agregado, y

2. La imposición de tipo selectivo al consumo.

$(\ldots)$

"Artículo 16.- Modificaciones al ordenamiento vigente.

Las modificaciones normativas que impliquen alteración en el importe tributario por pagar, sólo podrán empezar a aplicarse a partir del período fiscal siguiente, a la fecha de promulgación de la norma fiscal correspondiente".

Quiere decir entonces que cualquier País Miembro de la Comunidad Andina que desee modificar sus tributos en materia de imposición indirecta (por ejemplo, el ISC), tiene que cumplir con el precitado artículo 16 de la Decisión 599 y aplicar dicha modificación a partir del año (período fiscal) siguiente a la fecha de su promulgación.

\section{iii. Regulación bilateral - Las reglas de los TLCs}

a. Los impuestos indirectos a la luz de las normas contenidas en los Tratados de Libre Comercio suscritos por el Perú

\section{- $\quad$ Principios de Publicidad y Transparencia}

$\mathrm{Al}$ igual que en el marco de la $\mathrm{OMC}$, dentro de los compromisos asumidos por el Perú en los Tratados de Libre Comercio (en adelante, "TLC)" se incluyen las normas relacionadas a los principios de publicidad y transparencia, las cuales se basan por lo general en la normativa OMC analizada previamente.

Al respecto, el Perú tiene vigentes los siguientes TLC que regulan dichos principios: Estados Unidos, Unión Europea, Japón, México, China, Chile, Canadá, Costa Rica, Corea del Sur, Panamá, MERCOSUR, Tailandia; Alianza Pacífico, entre otros.

Por citar un ejemplo, el capítulo 19 del APC Perú - EE.UU., correspondiente a transparencia establece lo siguiente:

“Artículo 19.2: Publicación

1. Cada Parte se asegurará de que sus leyes, reglamentos, procedimientos, y resoluciones administrativas de aplicación general referentes a cualquier asunto comprendido en este Acuerdo, se publiquen prontamente o de otra forma sean puestos a disposición para conocimiento de las personas y Partes interesadas.

2. En la medida de lo posible, cada Parte deberá:

(a) publicar por adelantado cualquier medida que se proponga adoptar; y 
(b) brindar a las personas y Partes interesadas oportunidad razonable para formular observaciones sobre las medidas propuestas." (Énfasis agregado).

Es decir, cualquier norma de carácter general que el Perú desee promulgar, y que contemple cualquier asunto desarrollado en el citado TLC, debe ser publicada prontamente, procurando otorgar un período de consultas con las partes interesadas para su puesta en vigencia. El texto de dicho principio, sin embargo, es relativo, no siendo obligatorio su cumplimiento (únicamente una recomendación).

Distinto escenario nos encontramos en el apartado 1 del artículo 288 correspondiente al título de transparencia del Acuerdo Comercial Perú - UE, el cual señala que:

“Cada Parte garantizará que sus medidas de aplicación general, incluyendo leyes, reglamentos, decisiones judiciales, procedimientos y resoluciones administrativas que se refieran a cualquier asunto contemplado en este Acuerdo, sean publicadas sin demora o se pongan de otra manera a disposición de las personas interesadas de forma que puedan conocer su contenido." (Énfasis agregado).

Es relevante señalar que este Acuerdo, a diferencia de otros tratados comerciales firmados por el Perú, tiene carácter obligatorio. Además, tiene otra diferencia sustancial: permite la aplicación del Acuerdo a todas las medidas tributarias, con excepción de los supuestos señalados expresamente en la propia cláusula de reserva tributaria ${ }^{19}$. Un esquema de este tipo tiene una incidencia mayor en la potestad tributaria del Estado, en el ejercicio de las facultades de la Administración Tributaria y, en general, en cualquier requisito, acto o práctica tributaria, porque estarán limitados por todas las obligaciones pactadas en el Acuerdo. Por tanto, cualquier principio comercial, como el de transparencia, establecido en dicho Acuerdo, no puede ser obviado por el Estado bajo la premisa de estar limitando su ejercicio de potestad tributaria ${ }^{20}$.

De las disposiciones señaladas anteriormente, podemos mencionar que dichos Acuerdos establecen un compromiso amplio respecto al principio de publicación, bajo el cual no solo se debe publicar las normas de carácter general sino además los proyectos normativos. En este sentido, el Gobierno Peruano se ha obligado a pre-publicar cualquier medida que proponga adoptar que tenga un impacto en las

19 En su mayoría, las excepciones se vinculan al tratamiento tributario entre residentes y no residentes, las normas para luchar contra la evasión o elusión, y la primacía de los convenios de doble imposición sobre las obligaciones asumidas en el Acuerdo.

20 CHIRI GUTIÉRREZ, Isabel. Los Alcances de la Cláusula de Excepción Tributaria de los Tratados de Libre Comercio Una Referencia al TLC Perú - EE.UU. En Derecho y Sociedad núm. 33, Lima, (2009), pp. 82-95. 
operaciones de comercio exterior, las cuáles deben estar alineadas con los principios tanto de la OMC (GATT 94) como los del propio Acuerdo Comercial21.

\section{- $\quad$ Principios de acceso y permanencia a la inversión extranjera}

Considerando la relevancia particular de los principios de acceso y permanencia a la inversión extranjera, en tanto estos resultan un instrumento fundamental de las estrategias de los países para atraer inversión extranjera en el marco de los TLC's. Resulta necesario analizar si en este caso en particular, las modificaciones realizadas a al ISC tienen incidencia en las obligaciones internacionales adquiridas, afectando directamente o indirectamente a los inversionistas de estos países.

A manera de ejemplo procederemos a analizar el conjunto de disposiciones en materia de inversión contenidas en el Capítulo $X$ del Acuerdo de Promoción Comercial entre Estados Unidos y Perú, que establece lo siguiente:

"Artículo 10.28: Definiciones

"(...) inversión significa todo activo de propiedad de un inversionista o controlado por el mismo, directa o indirectamente, que tenga las características de una inversión, incluyendo características tales como el compromiso de capitales $\mathrm{u}$ otros recursos, la expectativa de obtener ganancias o utilidades, o la asunción de riesgo. (...)

Artículo 10.7: Expropiación e Indemnización 22

1. Ninguna de las Partes puede expropiar ni nacionalizar una inversión cubierta, sea directa o indirectamente mediante medidas equivalentes a la expropiación o nacionalización ("expropiación"), salvo que sea:

(a) por motivos de propósito público;

(b) de una manera no discriminatoria;

(c) mediante el pago pronto, adecuado y efectivo de la indemnización; y

(d) con apego al principio del debido proceso y al Artículo 10.5.

Anexo 10-B Expropiación Las Partes confirman su común entendimiento de que:

1. Un acto o una serie de actos de una Parte no pueden constituir una expropiación a menos que interfiera con un derecho de propiedad tangible o intangible o con los atributos o facultades esenciales del dominio de una inversión.

21 Es pertinente señalar que mediante Decreto Supremo Nº01 -2009-JUS se aprobó el reglamento que establece disposiciones relativas a la publicidad y publicación de proyectos normativos de normas legales de carácter general (en adelante, "el Reglamento"), el cual implementa lo establecido en el APC Perú -EEUU respecto a normas de transparencia. El mencionado Reglamento, en su artículo 14 estableció que las entidades públicas dispondrán la publicación de los proyectos de normas de carácter general en sus portales electrónicos o mediante cualquier otro medio, en un plazo no menor de treinta (30) días antes de la fecha prevista para su entrada en vigencia, salvo casos excepcionales (Ej. cuando resulta impracticable, innecesario o contraria a la seguridad o interés público, lo cual no aplica en el presente caso).

22 El Artículo 10.7 será interpretado de acuerdo con lo dispuesto en el Anexo 10-B. 
2. El Artículo 10.7.1 aborda dos situaciones. La primera es la expropiación directa, en donde una inversión es nacionalizada o de otra manera expropiada directamente mediante la transferencia formal del título o del derecho de dominio.

3. La segunda situación abordada por el Artículo 10.7.1 es la expropiación indirecta, en donde un acto o una serie de actos de una Parte tienen un efecto equivalente al de una expropiación directa sin la transferencia formal del título o del derecho de dominio.

(a) La determinación de si un acto o una serie de actos de una Parte, en una situación de hecho específica, constituye una expropiación indirecta, requiere de una investigación factual, caso por caso, que considere entre otros factores:

(i) el impacto económico del acto gubernamental, aunque el hecho de que un acto o una serie de actos de una Parte tenga un efecto adverso sobre el valor económico de una inversión, por sí solo, no establece que una expropiación indirecta haya ocurrido;

(ii) la medida en la cual la acción del gobierno interfiere con expectativas inequívocas y razonables de la inversión; y

(iii) el carácter de la acción gubernamental.

(b) Salvo en circunstancias excepcionales, no constituyen expropiaciones indirectas los actos regulatorios no discriminatorios de una Parte que son diseñados y aplicados para proteger objetivos legítimos de bienestar público, tales como la salud pública, la seguridad y el medioambiente"

De un análisis de lo expuesto, podemos apreciar que las modificaciones al ISC, al comprender disposiciones legales y vinculantes carentes de sustento técnico y fáctico, podrían configurar una expropiación indirecta a la luz del artículo 10.7 del referido Acuerdo. En tanto su manifiesta irrazonabilidad y carácter confiscatorio pueden generar repercusiones en la esfera del inversionista extranjero.

\section{iv. Regulación nacional - Las garantías generales a la liberalización de comercio exterior en el Perú}

\section{a. Los principios de la Constitución Política del Perú y el Decreto Legislativo $\mathrm{N}^{\circ} 668$ en materia de Comercio Internacional}

Conforme a lo previsto en la Constitución Política del Perú y en la normativa sectorial desarrollada desde la década de 1990, en el Perú la libre voluntad es un componente esencial del derecho a la libertad de empresa, así como el acceso al mercado empresarial.

Si bien el Estado tiene atribución constitucional para establecer ciertas limitaciones al ejercicio del derecho a la libertad de empresa con el fin de salvaguardar el interés público, las mismas deben ser aplicadas siempre y cuando no sean de tal magnitud que afecten el objeto de dicho derecho, es decir, que en desarrollo de la facultad de intervención económica, el Estado no pueda tener injerencia en la producción, distribución, utilización y consumo de los bienes, o genere obstáculos o barreras al libre comercio de determinados productos. Igualmente, la creación de normas 
limitativas a la libertad de empresa debe procurar desarrollarse de manera excepcional, cuando exista la verdadera necesidad de corregir alguna imperfección en el mercado que ponga en peligro el bien común.

Por otro lado, nuestro ordenamiento jurídico también reconoce el derecho fundamental a la protección de la salud, donde el Estado debe buscar que todas las personas tengan una mejor calidad de vida, para lo cual debe invertir en la modernización y fortalecimiento de las instituciones, debiendo adoptar políticas, planes y programas en ese sentido ${ }^{23}$.

Es una obligación del Estado velar dentro de los procesos de tutela de derechos, el cumplimiento de medidas razonables que solucionen problemas legítimos, como el de la salud pública, sin que ello conlleve impedimentos para el desarrollo económico. Es decir, la obligación del Estado es conseguir un justo equilibrio entre el objetivo legítimo perseguido (Ej.: protección de la salud, medio ambiente) y la promoción empresarial.

La estructura normativa comercial peruana tiene su punto de partida con la emisión del Decreto Legislativo Nº 668 (en adelante, el “DL 668”), promulgado en septiembre de 1991, mediante el cual el Estado peruano garantiza la libertad de comercio exterior e interior "como condición fundamental para el desarrollo del país".

Es decir, es el Estado peruano el que fija un objetivo de mediano y/o largo plazo (liberalización del comercio exterior e interior), como una política nacional orientada estratégicamente al desarrollo del país.

De acuerdo a ello, los aspectos más importantes del DL 668 son los siguientes:

- Prohibición de aplicación de gravámenes en la importación, excepto los derechos arancelarios y los impuestos que gravan la venta interna de bienes ${ }^{24}$.

- Se eliminan las restricciones y medidas para-arancelarias ${ }^{25}$.

Este último punto tiene un límite, y es que no se entenderán como medidas paraarancelarias "las prohibiciones y medidas de emergencia que se requieran para asegurar la salud de la población y la seguridad externa26" (Énfasis agregado).

23 Tribunal Constitucional. Sentencia de fecha 20 de abril de 2004, recaída en el Expediente No. 29452003-AA/TC.

24 Uno de los aspectos fundamentales del DL 668 se encuentra en su artículo 9, el cual determina que: "En la importación, prohíbase la aplicación de sobretasas, alícuotas o cualquier otro gravamen con la sola excepción de los derechos arancelarios y de los impuestos que gravan también la venta interna de bienes."

25 Asimismo, el artículo 12 del DL 668 establece que el Estado peruano debe garantizar a cualquier persona natural o jurídica que realizar operaciones de comercio exterior "sin prohibiciones ni restricciones paraarancelarias de ningún tipo, quedando por lo tanto sin efecto las licencias, dictámenes, visaciones previas y consulares, registros de importación, registros de cualquier naturaleza y condicionamientos previos de cualquier naturaleza que afecten la importación o exportación de bienes"

26 Resolución No 0908-2004/TDC-INDECOPI; Exp. Nº01-2003-CRT/P. Tribunal de Defensa de la Competencia y de la Propiedad Intelectual (Sala de Defensa de la Competencia) pág. 5. 
Por lo anterior, es importante indicar que el ISC, si bien puede ser un impuesto que grava la venta, puede ser considerado una barrera para-arancelaria a la luz del DL 668. Esto bajo el sustento ya desarrollado de los conceptos expuestos en el marco de la OMC.

Adicionalmente, es plausible que la estructura y diseño de la imposición del ISC esté bajo el alcance de los términos del marco de barreras comerciales no arancelarias ante el INDECOPI - Decreto Legislativo N 1212, "Decreto Legislativo que refuerza las facultades sobre eliminación de barreras burocráticas para el fomento de la competitividad".

Dicho marco normativo tiene por objeto garantizar la seguridad de las operaciones de comercio internacional y eliminar las regulaciones excesivas que lo limiten. Así, INDECOPI tiene como función identificar y eliminar las barreras comerciales no arancelarias, contribuyendo al desarrollo de la inversión privada al permitir que dicha entidad cuente con herramientas efectivas para retirar aquellos obstáculos que impidan la realización de actividades económicas y operaciones de comercio exterior, restringiendo el acceso y permanencia de los agentes económicos.

El artículo 7 del citado Decreto Legislativo Nº 1212 brinda la siguiente definición de barreras comerciales no arancelarias:

"Se entiende por Barreras Comerciales no Arancelarias a toda exigencia, requisito, restricción, prohibición o cobro establecido por cualquier entidad de la Administración Pública en ejercicio de potestades de imperio o administrativas, carentes de legalidad o razonabilidad, que afecten la importación o exportación de bienes, desde o hacia el territorio nacional".

En el caso concreto, el diseño y estructura del ISC puede ser considerada una barrera comercial no arancelaria, y por tanto, puede ser denunciada para su inaplicación, por los siguientes motivos:

(i) Se encuentra dentro de la definición de barrera comercial no arancelaria. El ISC puede ser una exigencia y/o cobro emitido por un órgano de la Administración Pública, dentro del ejercicio de su potestad de imperio, que incide perjudicialmente sobre la importación al territorio nacional, la cual resulta ilegal y/o carente de razonabilidad ${ }^{27}$. Además, como ya mencionamos previamente en el presente informe, en el marco de la OMC y el DL 668, el ISC puede ser considerado una medida no arancelaria restrictiva al comercio ${ }^{28}$.

27 Artículo 7 del Decreto Legislativo $N^{\circ} 1212$ : "Se entiende por Barreras Comerciales no Arancelarias a toda exigencia, requisito, restricción, prohibición o cobro establecido por cualquier entidad de la Administración Pública en ejercicio de potestades de imperio o administrativas, carentes de legalidad o razonabilidad, que afecten la importación o exportación de bienes, desde o hacia el territorio nacional".

28 En esta misma línea, el artículo 26 de la Ley de Organización y Funciones del INDECOPI establece que "corresponde a la Comisión de Dumping, Subsidios y Eliminación de Barreras Comerciales No Arancelarias velar por el cumplimiento de las normas que persiguen evitar y corregir el daño en el mercado provocado por prácticas de dumping o subsidios, a través de la imposición de derechos antidumping o compensatorios; actuar como autoridad investigadora en 
Así, la Comisión de Dumping, Subsidios y Eliminación de Barreras Comerciales No Arancelarias (la "Comisión") tiene competencia para efectuar el control posterior de aquellas disposiciones de la Administración Pública que limiten la importación o exportación de bienes en el país mediante la imposición de medidas no arancelarias carentes de legalidad y/o razonabilidad.

Según lo anterior, la Comisión tiene claramente potestad para analizar si la imposición del ISC es una medida no arancelaria ilegal y/o carente de razonabilidad, ya que esta se encuentra dentro de los alcances de su definición tanto en el Decreto Legislativo N 1212 como en los Acuerdos de la OMC.

(ii) No necesariamente es una medida exceptuada para ser calificada como barrera comercial no arancelaria: La definición de medida no arancelaria desarrollada en el Artículo 7 del Decreto Legislativo $N^{\circ} 1212$ señala tres (3) excepciones en cuanto al alcance del procedimiento de eliminación de barreras burocráticas no comerciales, estableciendo que:

"(...) no corresponde a la Comisión de Dumping, Subsidios y Eliminación de Barreras Comerciales no Arancelarias efectuar el control posterior o eliminación de las barreras comerciales no arancelarias contenidas en normas con rango de ley, ni sobre sanciones administrativas $u$ otras medidas expresamente exceptuadas de dicha calificación por norma con rango de ley".

En lo que respecta a este último punto, cabe señalar que la medida materia de cuestionamiento no calza dentro de los supuestos de las excepciones planteadas por la citada norma. Si bien generalmente la aplicación del ISC se aprueba con normas con rango de Ley, el objeto de su cuestionamiento no radica en el incremento ni en la exigencia del ISC per se, sino que radica en ciertos elementos contenidos en otras normas con rango jerárquico inferior.

\section{Conclusiones}

De acuerdo a la normativa comercial vigente del Perú, los impuestos indirectos, tales como el ISC, son susceptibles de ser analizados bajo la óptica de los principios del Comercio Internacional. Ello significa que este tipo de impuestos no deberán ser incongruentes con las disposiciones que proscriben la imposición de barreras injustificadas al comercio, el principio de no discriminación y de transparencia.

Asimismo, cabe resaltar que si bien en los TLC se han establecido ciertas excepciones en la regulación de materia tributaria, esto no significa que exista un margen de discrecionalidad absoluto en la emisión de medidas de este carácter. Una lectura adecuada de las disposiciones del Tratado correspondiente en

procedimientos conducentes a la imposición de medidas de salvaguardia; y, efectuar el control posterior y eliminación de barreras comerciales no arancelarias, de conformidad con lo dispuesto en los acuerdos internacionales suscritos por el Perú, los compromisos contraídos en el marco de la Organización Mundial del Comercio, los acuerdos de libre comercio, y las normas supranacionales y nacionales vigentes correspondientes". 
conjunción con los principios rectores del Comercio Internacional, habilitará la posibilidad de cuestionar si una medida específica en materia tributaria colisiona con una norma de carácter internacional.

A propósito de las modificaciones realizadas en mayo de este último año, podemos apreciar que estas medidas contienen una serie de elementos que no son conformes con la normativa comercial vigente del Perú tanto en el ámbito nacional (barreras comerciales no arancelarias) como en el marco de los compromisos internacionales suscritos (OMC, de los TLC y de la Comunidad Andina).

En virtud de lo expuesto podemos apreciar que a través de la emisión de estas modificaciones se ha vulnerado los principios de publicidad y transparencia a la luz del artículo X del GATT 94 en el marco de la OMC y de los TLC ratificados por el Perú.

Por otro lado, es menester resaltar también que estas modificaciones también son susceptibles de ser analizadas a la luz del marco normativo relativo a inversiones. No obstante, ello requerirá de una revisión reflexiva del diseño y estructura de la medida cuestionada a fin de determinar si esta genera algún perjuicio directo o indirecto a los inversionistas extranjeros.

A manera de conclusión, es necesario resaltar la importancia de las normas aplicables de Comercio Internacional en materia de calidad regulatoria. Una correcta adecuación de la normativa interna conforme a la normativa vinculante de comercio internacional, en el presente caso, contribuirá a mejorar la calidad y predictibilidad regulatoria en materia tributaria en el país. 